\title{
O carste e a qualidade das águas superficiais da bacia hidrográfica do rio Sucuri, Bonito/MS
}

\author{
Karst and surface water quality in the Sucuri River watershed, Bonito/MS
}

\author{
Rafael Brugnolli Medeiros \\ Doutor em Geografia pela \\ Universidade Federal da Grande Dourados, Brasil \\ rafael bmedeiros@hotmail.com
}

André Geraldo Berezuk Doutor em Geografia e Docente da Universidade Federal da Grande Dourados, Brasil andreberezuk@ufgd.edu.br

André Luiz Pinto

Doutor em Geociências e Meio Ambiente e Docente da Universidade Federal de Mato Grosso do Sul, Brasil andrepintofontanetti@gmail.com

Marcos Norberto Boin

Geólogo e Doutor em Geociências e Meio Ambiente pela Universidade Estadual Paulista Júlio de Mesquita Filho, Brasil marnorboin@gmail.com

Lorrane Barbosa Alves Doutoranda em Geografia da Universidade Federal da Grande Dourados, Brasil lorrane.iza@bol.com.br

\section{Resumo}

Essa pesquisa teve como objetivo analisar a influência dos litotipos de composição carbonática na qualidade das águas superficiais da Bacia Hidrográfica do Rio Sucuri - BHRS, localizada no município de Bonito - Mato Grosso do Sul, Brasil. Para tanto, a metodologia consistiu em duas etapas básicas: a primeira delas trata-se da atualização do mapa geológico da bacia, por meio de saídas de campo; e a segunda etapa consistiu no monitoramento da qualidade das águas superficiais ao longo de cinco pontos, selecionados no rio Sucuri. Chegou-se, assim, a resultados que apontaram a influência significativa das rochas carbonatadas na composição química e na qualidade das águas, seja em seu pH alcalino, alta condutividade e na concentração de sólidos totais dissolvidos - TDS, decorrente da quantidade de sais dissolvidos na água. Com isso, seu enquadramento apontou alguns pontos críticos, porém, quando relacionado ao parâmetro principal, as concentrações de oxigênio dissolvido - OD revelaram boa qualidade das águas. O parâmetro referente à turbidez é o impacto mais notável da geologia sobre as águas, pois ocorre a decantação dos componentes químicos dissolvidos dos calcários no leito fluvial, provocando uma translucidez que traz grande beleza cênica ao manancial. Conclui-se que, por meio dessa análise, foi possível enquadrar o rio Sucuri na classe I, limitando seu uso para determinadas funções, além de apontar que o ambiente cárstico exerce forte influência sobre os parâmetros físicos e químicos das águas superficiais.

Palavras-chave: sistema cárstico, qualidade físico-química da água, substrato rochoso, Mato Grosso do Sul. 


\begin{abstract}
This research aimed to analyze the influence of lithotypes of carbonate composition on the quality of the surface waters of the Sucuri River Basin - BHRS, located in the municipality of Bonito Mato Grosso do Sul, Brazil. To this end, the methodology consisted of two necessary steps: the first is the updating of the geological map of the basin, through field trips; and the second stage consisted of monitoring the quality of surface water along with five points, selected on the Sucuri River. Thus, results were reached that pointed out the significant influence of carbonated rocks on the chemical composition and water quality, be it in its alkaline $\mathrm{pH}$, high conductivity and the concentration of total dissolved solids - TDS, due to the amount of dissolved salts in the water. With this, its framework pointed out some critical points; however, when related to the primary parameter, the concentrations of dissolved oxygen - OD revealed good water quality. The parameter referring to turbidity is the most notable impact of geology on the waters, as the chemical components dissolved from the limestones in the riverbed decant, causing a translucency that brings great scenic beauty to the source. It is concluded that, through this analysis, it was possible to classify the Sucuri River in class I, limiting its use for specific functions, in addition to pointing out that the karst environment has a strong influence on the physical and chemical parameters of surface waters.
\end{abstract}

Keywords karstic system, physicochemical quality of the water, rocky substrate, Mato Grosso do Sul.

\title{
1. INTRODUÇÃ̃O
}

Analisar bacias hidrográficas atualmente, inserido no contexto espacial e ambiental em que ocorrem interações intrínsecas de seus componentes físicos e antrópicos, é uma das formas de compreender a qualidade ambiental de uma determinada área. Dessa forma, os aspectos antrópicos desempenham intensa pressão sobre as bacias hidrográficas, consequentemente, alteram o equilíbrio e o funcionamento dos sistemas hídricos.

Por essa razão, é de fundamental importância compreender as fragilidades e potencialidades ambientais da bacia hidrográfica no que tange aos seus componentes biofísicos para, posteriormente, se entender as repercussões das interferências antrópicas. Piroli (2013), afirma que a bacia hidrográfica pode ser definida, quantificada e qualificada, a partir de seus processos físicos e químicos, que moldam o relevo e condicionam as relações entre seus componentes e considera a água como um elo entre todos os aspectos, sendo primordial para o equilíbrio desse sistema ambiental.

Oficialmente se define a bacia hidrográfica como unidade territorial de estudo, que no Brasil se deu a partir da Lei $n^{\circ}$ 9.433, de 8 de janeiro de 1997 (BRASIL, 1997), que agrupa princípios e normas para a gestão de seus mananciais. Já no âmbito do Estado de Mato Grosso do Sul, a Lei n 2.406, de 29 de janeiro de 2002 (MATO GROSSO DO SUL, 2002), instituiu a Política Estadual dos Recursos Hídricos - PERH e a criação do Sistema Estadual de Gerenciamento dos Recursos Hídricos - SEGRH, estabelecendo assim, como parte integrante do SEGRH, a criação dos Comitês de Bacia Hidrográfica - $\mathrm{CBH}$. 
Esse importante reconhecimento técnico, metodológico e institucional norteia o recorte espacial da bacia hidrográfica, sendo muito utilizada como unidade territorial de estudo e de planejamento. Seja pela obrigatoriedade, segundo as leis supracitadas, ou pela necessidade de compreensão das interações mútuas entre os componentes da paisagem e de seus subsistemas natural, construído, social, econômico e produtivo, todos estes modelando a paisagem ao longo do tempo (SILVA et al. 2016). Logo, algumas questões vêm à tona e embasam as discussões acerca da interferência dos aspectos físicos das bacias hidrográficas sobre os mananciais hídricos, mais precisamente, das rochas sobre a qualidade das águas superficiais, sobretudo em bacias hidrográficas cársticas.

No Brasil, há várias regiões cársticas (formações Caatinga, Carajás, Salinas, Vazante; grupos Açungui, Apodi, Araras, Bambuí, Brusque, Corumbá, Paranoá, Rio Pardo, Ubajara, Una, Vargem Grande, Xambioá; regiões cársticas de São João Del Rei, Quadrilátero Ferrífero; supergrupo Canudos), sendo uma delas localizada no planalto da serra da Bodoquena, que abrangem os municípios de Jardim, Bonito e Bodoquena no Mato Grosso do Sul, que logicamente são caracterizados por rochas ricas em carbonato dissolvido, que trazem particularidades naturais à qualidade das águas superficiais e subterrâneas, e culminam, portanto, em pHs alcalinos, altas condutividades elétricas e elevada translucidez das águas, exercendo relevante beleza cênica com grande atratividade turística.

A presente pesquisa norteou suas discussões, a fim de compreender essa relação entre as rochas e as características físicas e químicas das águas superficiais da Bacia Hidrográfica do Rio Sucuri - BHRS, localizada no município de Bonito, a sudoeste do Estado de Mato Grosso do Sul. Esta bacia hidrográfica está situada sobre rochas carbonatadas, que trazem consigo influência significativa sobre os parâmetros físicos e químicos, sobretudo pela elevada translucidez de suas águas.

Mesmo que as pesquisas sobre ambientes cársticos e os sistemas que nele se relacionam se tornem mais frequentes, tanto em quantidade como em qualidade, ainda são incipientes esses estudos, ainda mais aqueles que abrangem a influência do substrato rochoso sobre os demais componentes de uma bacia hidrográfica, mais precisamente, as águas. Logo, ainda faltam estudos relacionados às águas superficiais, especialmente em um município turístico como Bonito, onde as pesquisas sobre este recurso são variadas, mas não oferecem uma análise significativa acerca da influência das rochas nos parâmetros físicos e químicos das águas, seus estudos são mais voltados à atividade turística.

Para tanto, é necessário que ocorra, além das análises supracitadas, algumas comparações com pesquisas em sistemas fluviais do Mato Grosso do Sul, sempre voltados à temática da qualidade das águas e utilizando alguns dos parâmetros analisados nesta pesquisa. Sua comparação 
deve ser feita com sistemas terrígenos e cársticos, sendo encontrados alguns trabalhos referenciais como Pinto et al. (2010), Oliveira et al. (2011), Schautz (2015) e Brugnolli et al. (2017) para sistemas terrígenos e Silva et al. (2014), Lelis et al. (2015), Silva et al. (2016), Brugnolli et al. (2019) e Brugnolli (2020) para sistemas cársticos.

Monteiro et al. (1997) e Fritzsons (2003) trabalham com alguns dados importantes e que contribuíram para o entendimento dos impactos das rochas sobre os recursos hídricos. Os autores afirmam que não apenas as condicionantes litológicas alteram sua qualidade, mas o escoamento superficial por si só modifica todos os seus parâmetros. Fritzsons (2003) ainda enfatiza que, diante de seu intemperismo, as rochas carbonatadas possuem pouca permeabilidade e, devido à dissolução química do calcário calcítico e dolomítico, transmitem alterações significativas nos parâmetros de qualidade das águas, que também são influenciadas pelos demais componentes da paisagem.

Com isso, nota-se que a água, por si só, não apresenta informações claras a respeito da influência litológica, contudo, sua análise, bem como a interpretação dos parâmetros alterados, segundo o Conselho Nacional do Meio Ambiente - CONAMA (2005), além do conhecimento empírico da região, trazem consigo ideias claras a respeito da relação das rochas com os parâmetros de qualidade das águas.

Para contribuir no entendimento desses processos dinâmicos que ocorrem na BHRS, sobretudo na relação entre a litológica e os recursos hídricos, apresenta-se esta pesquisa que teve como objetivo a análise da influência das características litológicas sobre a qualidade das águas superficiais do rio Sucuri, que em sua totalidade, correm sobre terrenos cársticos.

\section{2. ÁREA DE ESTUDO}

A BHRS possui uma área de $6,69 \mathrm{~km}^{2}$, constitui-se em importante afluente do Rio Formoso, e seu canal principal possui apenas 1,83 km de extensão (Figura 1). Apesar de tratar-se de uma bacia hidrográfica de pequena extensão, é uma área de importância turística notável, sobretudo por suas águas translúcidas. 


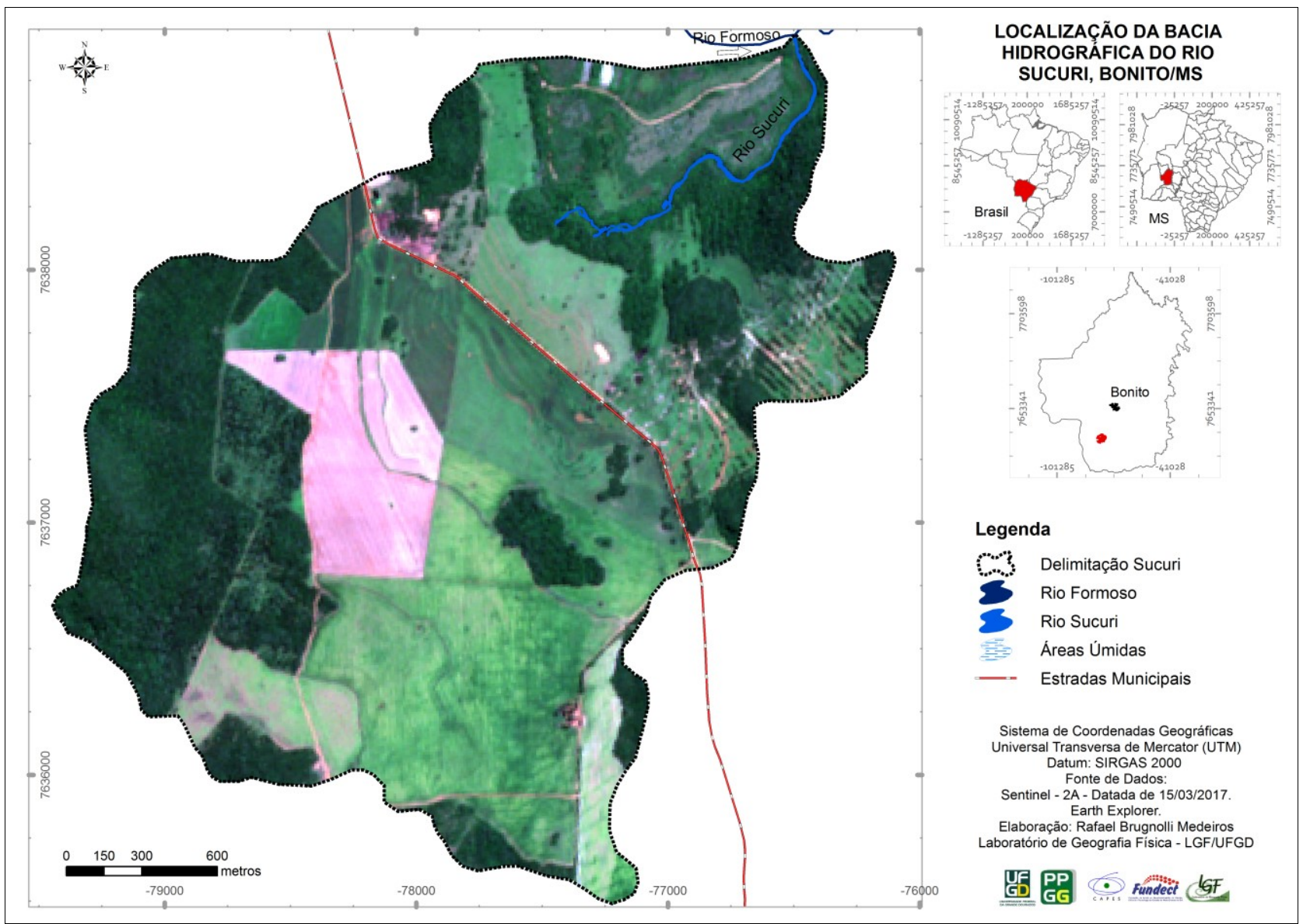

Figura 1 - Localização da Bacia Hidrográfica do Rio Sucuri, Bonito/MS.

\section{METODOLOGIA}

A metodologia operacional deste artigo consistiu em duas etapas básicas: a primeira delas, por meio do mapeamento da geologia da BHRS, empregando informações adquiridas juntamente à Companhia de Pesquisa de Recursos Minerais - CPRM (2006), cartas altimétricas e de imagens do satélite Sentinel 2A. Porém, devido à escala da base de dados do mapeamento do CPRM, foi necessário o reconhecimento de campo, para averiguação e maior detalhamento da espacialização das formações geológicas. Essas saídas de campo auxiliaram no mapeamento e na maior precisão do limite das estruturas, sendo fundamental para a construção dos mapas (confeccionados segundo o Sistema de Informação Geográfica - SIG ArcGis $10^{\circledR}$ ).

A segunda etapa consistiu na mensuração dos parâmetros físicos e químicos das águas superficiais da BHRS, utilizando o equipamento Horiba U-50 Series Multiparameter water Quality Unit's, para mensuração dos parâmetros de: Oxigênio Dissolvido - OD; Potencial Hidrogeniônico pH; Temperatura da água e do ar; Condutividade Elétrica - CE, Turbidez; Potencial Redox - ORP; e Sólidos Totais Dissolvidos - TDS e Salinidade. E ainda, do medidor de velocidade de fluxo da água, da Global Water, Global Flow Probe, modelo FP101 - FP201. 
Estas medidas foram realizadas em 5 pontos de monitoramento da qualidade das águas superficiais (Figura 2), que foram definidos segundo: facilidade do acesso por meio de trilhas dos atrativos turísticos; nascente; área de ressurgência; e pontos no alto, médio e baixo curso da BHRS.

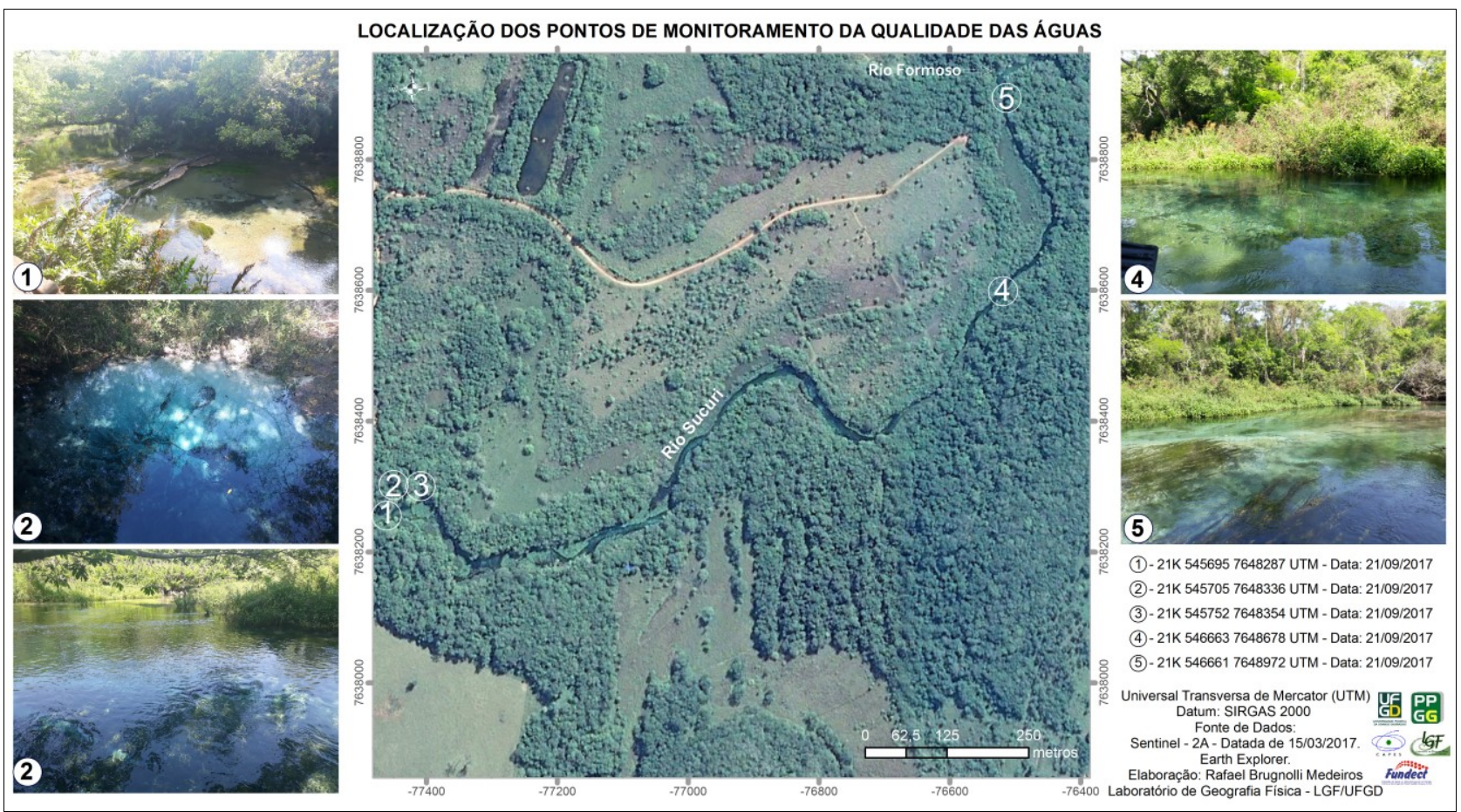

Figura 2 - Localização dos pontos de monitoramento da qualidade das águas.

O ponto 1 localiza-se nas áreas da nascente do rio Sucuri, em uma área com vegetação florestal. Apresenta diversas surgências (nascentes) e com muita vegetação aquática. O ponto 2 está localizado em uma das surgências do rio Sucuri, apresenta uma grande quantidade de matéria orgânica e vegetação de porte elevado.

O ponto 3 já se localiza à jusante, cerca de 100 metros das nascentes do rio Sucuri, apresenta uma vegetação florestal na margem esquerda, mas extensas áreas úmidas na margem direita. Já o ponto 4 se localiza no médio curso do rio Sucuri, com vegetações aquáticas nas duas margens. Após esses pontos, há pouca vegetação florestal, mas de porte elevado. Por fim, o ponto 5 se localiza a poucos metros da foz do rio Sucuri no rio Formoso, apresenta áreas úmidas e com uma vegetação de porte elevado em ambas as margens.

Em cada um destes cinco pontos de monitoramento das águas foi realizada a mensuração das águas e os dados foram analisados segundo a resolução 357/2005 do CONAMA (2005), que estabelece limites para as classes de enquadramento dos recursos hídricos doces superficiais no Brasil e recomenda os seus usos principais (Tabela 1). 
Tabela 1 - Limites dos parâmetros para enquadramento das águas superficiais.

\begin{tabular}{|c|c|c|c|c|c|c|c|c|}
\hline \multirow[b]{2}{*}{ Classes } & \multicolumn{8}{|c|}{ Enquadramento das Águas Superficiais } \\
\hline & OD & pH & $\begin{array}{c}\text { Turbi- } \\
\text { dez }\end{array}$ & $\mathbf{C E}$ & TDS & ORP & $\begin{array}{c}\text { Salini- } \\
\text { dade }\end{array}$ & $\begin{array}{c}\text { Principais Preconizações para a utilização das } \\
\text { Águas Superficiais }\end{array}$ \\
\hline Especial & $\begin{array}{c}>10,0 \\
\mathrm{mg} / \mathrm{L}\end{array}$ & $\begin{array}{c}6,0 \mathrm{a} \\
9,0\end{array}$ & $\begin{array}{l}0 \text { a } 20 \\
\text { NTU }\end{array}$ & $\begin{array}{l}0 \text { a } 50 \\
\mathrm{uS} / \mathrm{cm}\end{array}$ & $\begin{array}{c}0 \text { a } 200 \\
\mathrm{mg} / \mathrm{L}\end{array}$ & $\begin{array}{c}0 \text { a } 300 \\
\mathrm{mV}\end{array}$ & 0,00 & $\begin{array}{l}\text { Consumo humano com desinfecção; Preservação } \\
\text { de equilíbrio natural das comunidades aquáticas; } \\
\text { Preservação dos ambientes aquáticos em unidades } \\
\text { de conservação de proteção integral. }\end{array}$ \\
\hline $\mathbf{I}$ & $\begin{array}{l}10 \text { a } 6 \\
\mathrm{mg} / \mathrm{L}\end{array}$ & $\begin{array}{c}6,0 \mathrm{a} \\
9,0\end{array}$ & $\begin{array}{c}20 \text { a } 40 \\
\text { NTU }\end{array}$ & $\begin{array}{c}50 \text { a } 75 \\
\mathrm{uS} / \mathrm{cm}\end{array}$ & $\begin{array}{c}200 \mathrm{a} \\
300 \\
\mathrm{mg} / \mathrm{L}\end{array}$ & $\begin{array}{c}300 \mathrm{a} \\
400 \mathrm{mV}\end{array}$ & 0,00 & $\begin{array}{l}\text { Consumo humano, após tratamento simplificado; } \\
\text { Proteção das comunidades aquáticas; Recreação } \\
\text { de contato primário (natação e mergulho); } \\
\text { Irrigação de hortaliças que são consumidas cruas } \\
\text { e de frutas que se desenvolvam rentes ao solo e } \\
\text { que sejam ingeridas sem remoção de películas e à } \\
\text { proteção das comunidades aquáticas em Terras } \\
\text { Indígenas. }\end{array}$ \\
\hline II & $\begin{array}{l}6 \text { a } 5 \\
\mathrm{mg} / \mathrm{L}\end{array}$ & $\begin{array}{c}6,0 \mathrm{a} \\
9,0\end{array}$ & $\begin{array}{c}40 \text { a } 70 \\
\text { NTU }\end{array}$ & $\begin{array}{l}75 \text { até } \\
100 \\
u S / c m\end{array}$ & $\begin{array}{l}300 \mathrm{a} \\
400 \\
\mathrm{mg} / \mathrm{L}\end{array}$ & $\begin{array}{c}400 \mathrm{a} \\
500 \mathrm{mV}\end{array}$ & 0,00 & $\begin{array}{l}\text { Abastecimento para consumo humano, após } \\
\text { tratamento convencional, à proteção das } \\
\text { comunidades aquáticas, à recreação de contato } \\
\text { primário, tais como natação e mergulho, à } \\
\text { irrigação de hortaliças, plantas frutíferas e de } \\
\text { parques, jardins, campos de esporte e lazer, com } \\
\text { os quais o público possa vir a ter contato direto e } \\
\text { à aquicultura e à atividade de pesca. }\end{array}$ \\
\hline III & $\begin{array}{l}5 \mathrm{a} 4 \\
\mathrm{mg} / \mathrm{L}\end{array}$ & $\begin{array}{c}6,0 \mathrm{a} \\
9,0\end{array}$ & $\begin{array}{l}70 \text { a } \\
100 \\
\text { NTU }\end{array}$ & $\begin{array}{c}100 \mathrm{a} \\
150 \\
\mathrm{uS} / \mathrm{cm}\end{array}$ & $\begin{array}{l}400 \mathrm{a} \\
500 \\
\mathrm{mg} / \mathrm{L}\end{array}$ & $\begin{array}{c}500 \mathrm{a} \\
600 \mathrm{mV}\end{array}$ & 0,00 & $\begin{array}{l}\text { Abastecimento para consumo humano, após } \\
\text { tratamento convencional ou avançado, à irrigação } \\
\text { de culturas, cerealíferas, à pesca amadora, à } \\
\text { recreação de contato secundário e dessedentação } \\
\text { de animais. }\end{array}$ \\
\hline IV & $\begin{array}{c}<4 \\
\mathrm{mg} / \mathrm{L}\end{array}$ & $\begin{array}{c}6,0 \mathrm{a} \\
9,0\end{array}$ & $\begin{array}{l}>100 \\
\text { NTU }\end{array}$ & $\begin{array}{c}+150 \\
\mathrm{uS} / \mathrm{cm}\end{array}$ & $\begin{array}{l}>500 \\
\mathrm{mg} / \mathrm{L}\end{array}$ & $\begin{array}{l}>600 \\
\mathrm{mV}\end{array}$ & $>0,00$ & Navegação e à harmonia paisagística \\
\hline
\end{tabular}

Fonte: CONAMA (2005).

\section{RESULTADOS E DISCUSSÕES}

O contexto geológico da BHRS é definido por grupos de rochas carbonatadas, sendo o primeiro deles, representado pelo Grupo Corumbá, predominantemente composto por rochas calcárias calcíticas e dolomíticas, e o segundo pelo Grupo Cuiabá, constituído, na bacia, por mármores da Subunidade Carbonática (Figura 3).

A BHRS está localizada no planalto da serra da Bodoquena, sendo uma área de ambiente cárstico, e segundo Sallun Filho et al. (2009), essa região apresenta depósitos de calcários calcíticos muito finos, derivados da litificação das partículas clásticas carbonatadas, depósitos estes associados às drenagens da serra da Bodoquena. 


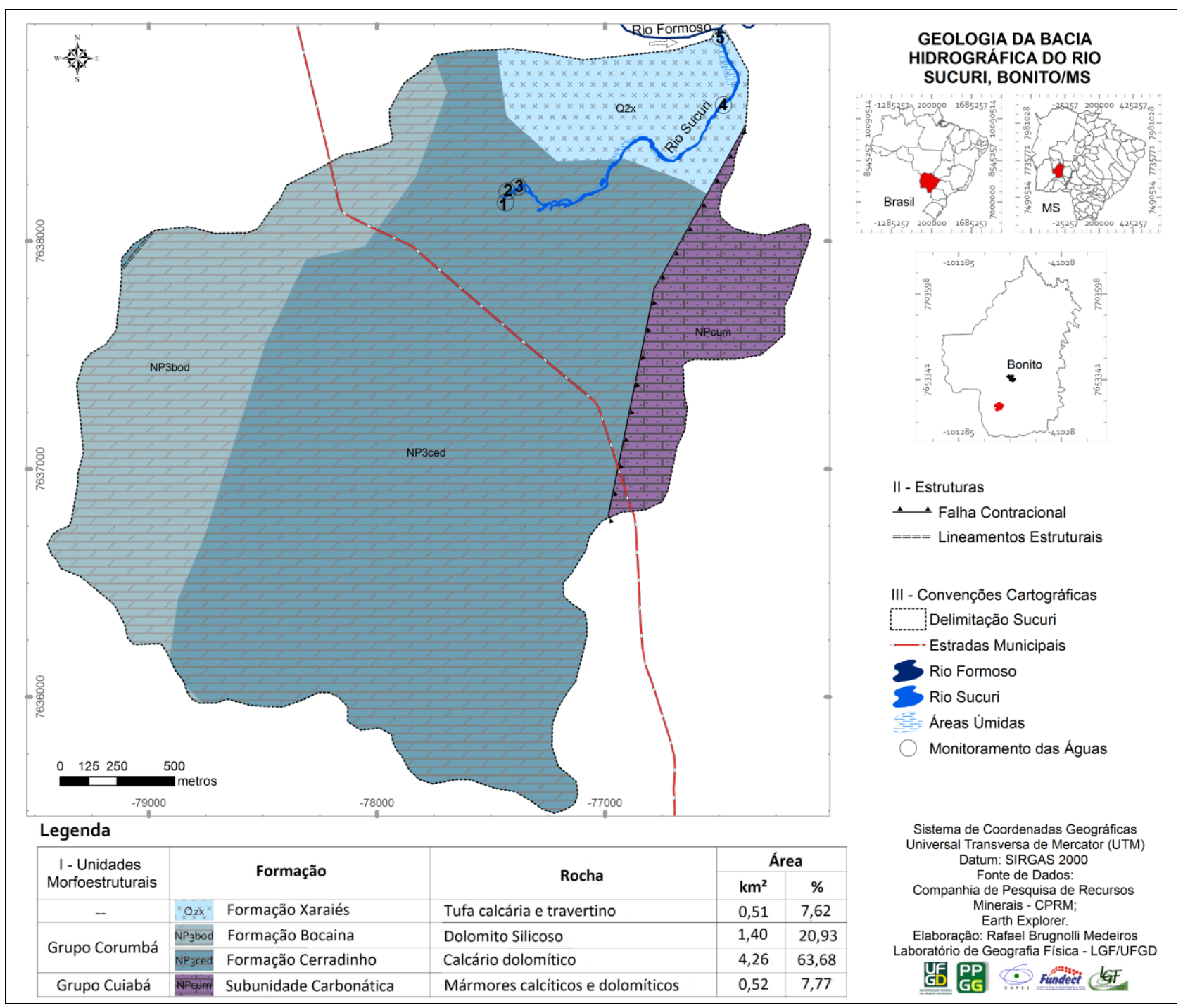

Figura 3 - Mapa Geológico da BHRS, Bonito/MS.

A formação mais antiga, encontrada na BHRS, pertence ao período Criogeniano (850 milhões a 630 milhões de anos) e é denominada de Subunidade Carbonática do Grupo Cuiabá, sendo caracterizado por seus mármores calcíticos e dolomíticos. Essas áreas são encontradas no leste da BHRS, em seu médio e baixo curso, onde a calcita ocorre em maior predominância, possuindo foliação metamórfica milimétrica, sendo representativo em áreas de falhas. Também ocorre, na bacia, às margens de sua borda oeste, uma falha contracional que abrange um total de $0,52 \mathrm{~km}^{2}$ ou aproximadamente $7,8 \%$ da BHRS, segundo dados adquiridos por meio da CPRM (2006).

$\mathrm{Na}$ sequência, encontra-se a Formação Cerradinho, pertencente ao Grupo Corumbá, constituída de rochas predominantemente carbonatadas, segundo a CPRM (2006). As porções intermediárias e superiores desta formação compreendem calcários calcíticos e dolomíticos, com intercalações de siltitos e arenitos. Inicia-se com intercalações de folhelhos marrom claros, amarelados e pretos laminados que se alternam com calcários cinza escuros e apresenta estratos cruzados. Os dolomitos são cinza claros, maciços e em lâminas com camadas alternadas de modo 
rítmico com o calcário. No caso da BHRS, a predominância é da dolomita, sendo encontrada em toda a região do alto curso.

A alteração destas rochas origina solos com alto teor de cálcio e magnésio que confere às terras alta fertilidade. Consequentemente são áreas onde ocorrem maior predominância das monoculturas de soja no planalto da serra da Bodoquena. Suas áreas de poljes, que são as regiões aplainadas e formadas pela dissolução do calcário, ocorrem em 4,26km² (63,68\% da área da bacia) e é onde se encontra localizada a nascente do rio Sucuri.

Pertencente ao mesmo Grupo Corumbá, a Formação Bocaina apresenta, na BHRS, a característica dolomítica silicosa, sendo encontrada em $1,40 \mathrm{~km}^{2}(20,93 \%$ da área $)$ no alto e médio curso da bacia, sobretudo próximo a sua borda oeste, com um relevo mais acidentado com morros residuais isolados, devido a maior resistência ao intemperismo da sílica. Essa formação, nas proximidades da serra da Bodoquena, tem por característica, segundo Boggiani (1997), apresentar pacotes maciços de dolomitos, sobre granitoides do Complexo Rio Apa, seguidos de dolomitos estratificados com intercalações de silexitos e quartzos associados às rochas carbonatadas.

Por fim, a formação mais jovem encontrada na BHRS, pertence ao período Quaternário, que é a Formação Xaraiés, caracterizada pelas tufas calcárias e travertinos, incrustados sobre as feições do leito fluvial. Devido ao seu alto teor de carbonato de cálcio e magnésio, ocorre a acreção do material em suspensão das águas superficiais, tornando-os mais densos e depositando no leito fluvial.

Portando, essa formação é bastante irregular e é um verdadeiro depósito de incrustações, quase sempre ausente de qualquer estrutura sedimentar. Esses calcários, no geral, possuem cor creme ou rosada, raramente avermelhada e trata-se de rochas consistentes com porosidade variável (BAPTISTA et al., 1984).

Logo, essas rochas resultam em águas alcalinas e Mantovani et al. (2016) ressalta que, devido à carstificação das rochas carbonatadas, ocorre um armazenamento de água subterrânea, adquirindo esta água, uma natureza alcalino-terrosa e cálcio-magnesiana. Essas formações encontram-se dispostas no médio e baixo curso da BHRS, ao longo de $0,51 \mathrm{~km}^{2}(7,62 \%$ da área). Segundo Sallun Filho et al. (2009, p.48), trata-se de uma deposição de tufas, originadas pelo alto teor de carbonato de cálcio dissolvido na água e que provoca alta translucidez e intensa atividade biológica. Sendo que Bonito representa "o mais expressivo registro de tufas na América do Sul, com intensa atividade turística face ao grande valor paisagístico e ambiental”.

As diferentes características litológicas cársticas resultam em feições morfológicas distintas, tais como: as dolinas, mogotes, poljes, sumidouros, ressurgências, uvalas, lapiás, feições ligadas à espeleogênese como cavernas, lagos subterrâneos, dutos subterrâneos, dentre outras feições cársticas. Na BHRS ocorre ainda uma relação estreita das rochas com o uso antrópico 
(Figura 4), pois a fertilidade do solo advinda do calcário, somado ao relevo plano, favorece a entrada de culturas de soja.

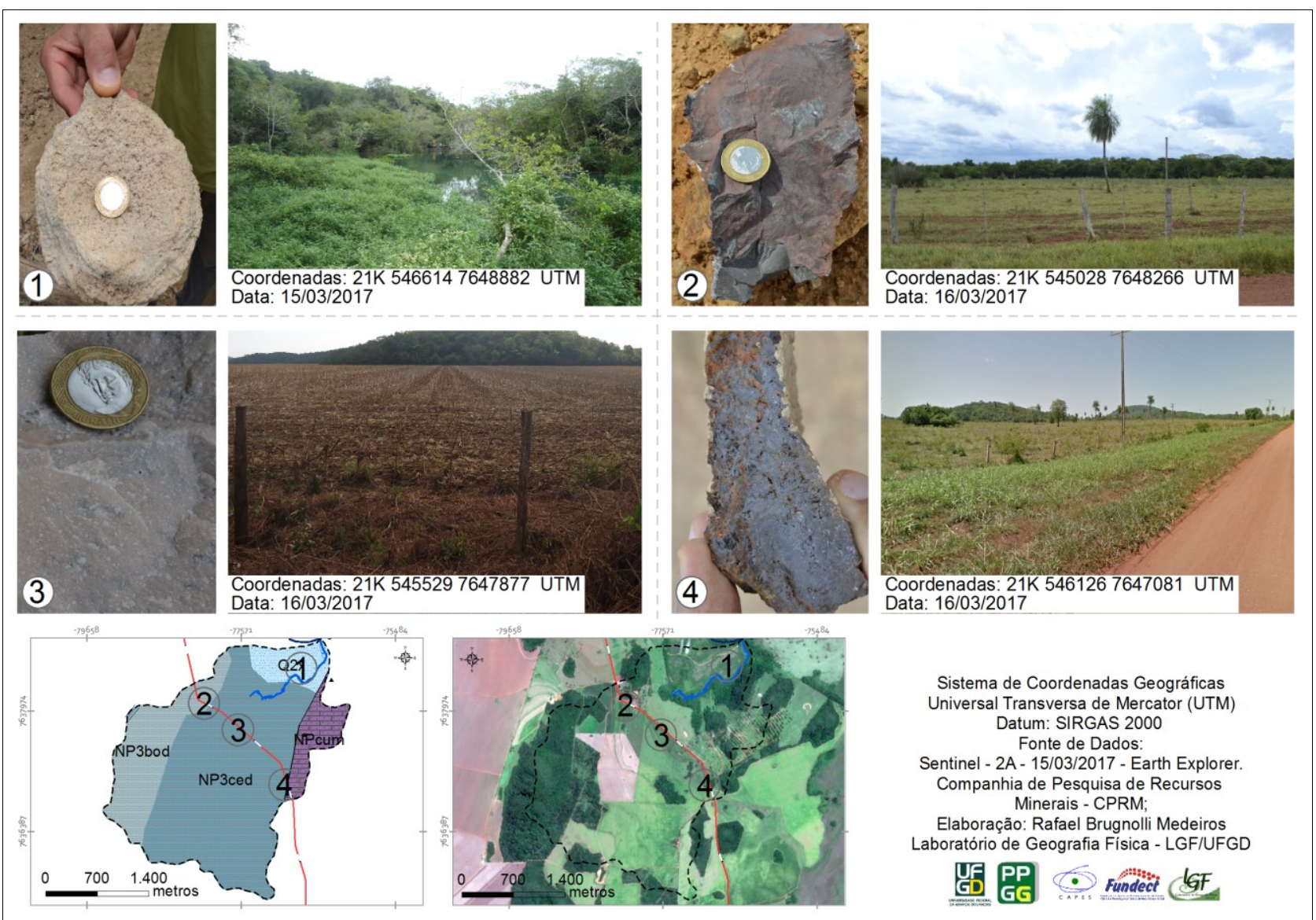

Figura 4 - Foto 1 - Tufas calcárias na planície do rio Sucuri; Foto 2 - Calcário dolomítico da Formação Bocaina no divisor de águas da BHRS; Foto 3 - Calcário dolomítico da Formação Cerradinho nas áreas de poljés da BHRS; e Foto 4 - Mármore dolomítico da Subunidade Carbonática do Grupo Cuiabá.

$\mathrm{Na}$ análise da qualidade das águas da BHRS, identificam-se as influências das rochas carbonatadas (calcários calcíticos, dolomito silicoso e tufas calcárias) sobre os parâmetros físicoquímicos das águas, ao longo dos cinco pontos de monitoramento. Assim, o município de Bonito, e mais precisamente na BHRS, possui processos hidrogeológicos particulares, com as águas superficiais apresentando uma elevada translucidez (Tabela 2).

A nascente do rio Sucuri (ponto 1) possui natureza difusa, com diversos afloramentos e nascentes das águas subterrâneas e presença das rochas da Formação Cerradinho, com seus calcários dolomíticos. O contato da água com o ambiente, por meio dos processos físicos, químicos e biológicos, acaba elevando o OD para $8,88 \mathrm{mg} / \mathrm{L}$.

Além disso, a turbidez se apresentou de forma muito reduzida, principalmente por esta área não apresentar grande velocidade de fluxo e devido à proibição da entrada de turistas no local, fazendo com que não ocorra um pisoteio do leito, permanecendo com seus parâmetros naturais, sem alçar sedimentos do leito fluvial. 
Outro destaque importante e que altera a turbidez do local, é a grande quantidade de nascentes que, em contato com o carbonato de cálcio, favorecem a decantação dos sedimentos químicos compostos por $\mathrm{CaCO}^{3}$ e $\mathrm{CaMg}\left(\mathrm{CO}^{3}\right)^{2}$, alcançando apenas 0,55 NTU. Em comparação com outras regiões cársticas e terrígenas do Mato Grosso do Sul, essa turbidez se mostra, portanto, altamente influenciada pelas rochas calcárias.

Tabela 2- Resultados dos parâmetros de qualidade das águas superficiais da BHRS, no verão de 2017.

\begin{tabular}{|c|c|c|c|c|c|}
\hline Pontos & 1 & 2 & 3 & 4 & 5 \\
\hline $\begin{array}{l}\text { Curso } \\
\text { Fluvial }\end{array}$ & $\begin{array}{c}\text { Rio Sucuri - } \\
\text { Nascente }\end{array}$ & $\begin{array}{l}\text { Rio Sucuri - } \\
\text { Ressurgência }\end{array}$ & $\begin{array}{c}\text { Rio Sucuri - } \\
\text { Alto Curso }\end{array}$ & $\begin{array}{l}\text { Rio Sucuri - } \\
\text { Médio Curso }\end{array}$ & $\begin{array}{c}\text { Rio Sucuri - } \\
\text { Foz }\end{array}$ \\
\hline Horário & 09:00 & $09: 16$ & 09:20 & $16: 10$ & $16: 26$ \\
\hline Latitude S (UTM) & 7648287 & 7648337 & 7648354 & 7648679 & 7648974 \\
\hline Longitude O (UTM) & 545696 & 545705 & 545753 & 546663 & 546659 \\
\hline $\mathrm{OD}(\mathrm{mg} / \mathrm{L})$ & 8,88 & 5,03 & 6,17 & 8,44 & 8,17 \\
\hline $\mathrm{CE}(\mu \mathrm{S} / \mathrm{cm})$ & 538,00 & 538,00 & 539,00 & 539,00 & 537,00 \\
\hline $\mathrm{pH}$ & 7,50 & 7,79 & 7,70 & 7,92 & 7,73 \\
\hline Turbidez (NTU) & 0,55 & 0,62 & 0,73 & 0,88 & 0,16 \\
\hline Velocidade $(\mathrm{m} / \mathrm{s})$ & 0,83 & 0,01 & 7,08 & 19,17 & 18,33 \\
\hline Temperatura do $\operatorname{Ar}\left({ }^{\circ} \mathrm{C}\right)$ & 28,36 & 27,25 & 26,6 & 29,31 & 28,02 \\
\hline Temperatura da Água $\left({ }^{\circ} \mathrm{C}\right)$ & 26,21 & 25,47 & 24,77 & 25,31 & 25,27 \\
\hline ORP (mV) & 200,00 & 192,00 & 163,00 & 151,00 & 155,00 \\
\hline TDS (mg/L) & 344,00 & 345,00 & 344,00 & 344,00 & 346,00 \\
\hline Salinidade (\%) & 0,03 & 0,03 & 0,03 & 0,03 & 0,03 \\
\hline Classes de Enquadramento & $\mathrm{I}$ & II & $\mathrm{I}$ & $\mathrm{I}$ & I \\
\hline $\begin{array}{l}\text { Classe Especial de Enquadran } \\
\text { Classe I de Enquadramento } \\
\text { Classe II de Enquadramento } \\
\text { Classe III de Enquadramento } \\
\text { Classe IV de Enquadramento }\end{array}$ & nento & & & & \\
\hline
\end{tabular}

Segundo Brugnolli (2016), a turbidez em outras regiões chega em torno de 17,00 NTU, alcançando, em alguns pontos, acima de 200 NTU (valor este levando em consideração, que sua área é de característica terrígena, localizada no setor leste do Estado). Outros trabalhos a fim de comparação devem ser citados, como o de Pinto et al. (2011) onde a turbidez, em termos normais, variou de 7,00 NTU a 65,00 NTU em áreas como o córrego Bom Jardim, no município de Brasilândia, também no extremo leste do Estado do Mato Grosso do Sul. Essas variações nas áreas terrígenas contrastam com os aspectos encontrados em regiões cársticas, como por exemplo, os trabalhos de Lelis et al. (2015) e Brugnolli (2020) que analisaram o rio Formoso e Brugnolli et al. (2019) discutindo sobre o rio Mimoso, constataram que a turbidez em águas superficiais de sistemas cársticos girou em torno de 0,80 NTU a 3,00 NTU.

Outro fator de destaque, nesse ponto 1, é a condutividade elétrica muito elevada, chegando a $534 \mu \mathrm{S} / \mathrm{cm}$, ocasionado, principalmente, pela dissolução dos altos teores de calcário puro das formações Cerradinho e Xaraiés. Há, no ponto 1, alto nível de sólidos totais dissolvidos, decorrentes da presença de carbonatos, bicarbonatos e magnésio, que também contribuem para a elevação da CE. Isso ainda é corroborado por Bartmann (2015), que pesquisou a qualidade das águas da bacia 
hidrográfica do rio Miranda - BHRM, trabalho importante, pois o rio Sucuri é uma de suas subbacias. A BHRM exibe dois ambientes (cárstico e terrígeno) e o autor compreendeu que a condutividade em ambientes cársticos é muito superior daqueles terrígenos devido ao contato com os minerais condutores das rochas carbonatadas.

Em trabalhos como o de Oliveira et al. (2011) e Schautz (2015), a condutividade elétrica gira em torno de 30 a $50 \mu \mathrm{S} / \mathrm{cm}$, muito inferior aos valores encontrados no trabalho de Lelis (2015) e Brugnolli et al. (2019), chegando em torno de $400 \mu \mathrm{S} / \mathrm{cm}$, mas ainda inferior ao encontrado na presente pesquisa, por ser um manancial (rio Sucuri) de pequena extensão, suas águas mantêm características hidrogeológicas, e seu contato com as rochas calcárias dolomíticas e calcíticas elevam o TDS e, consequentemente, a CE.

Essa composição calcária da região influi em um pH que alcança a 7,50. Neste ponto 1, por mais que seja preservada a sua mata ciliar, apresenta-se algumas questões locais que merecem destaque, tais como a entrada e pressão intensa das culturas de soja sobre a área de vegetação nativa. Estas culturas, em épocas mais chuvosas, onde o escoamento superficial é maior, proporcionam problemas ambientais relacionados ao turvamento das águas do rio Sucuri.

$\mathrm{O}$ pH é um dos parâmetros menos alterados, em comparação com outras regiões. Este pH é mais elevado do que em áreas terrígenas, sobretudo devido às águas ricas em $\mathrm{CaCO}^{3}$ (alcalinas) porém, em menores variações do que outros parâmetros. Comparando-a com outras regiões, Lelis (2015) aponta valores próximos a 8 de pH nos rios Mimoso e Formoso (cársticos), já Brugnolli et al. (2017) traz valores perto dos 6 e 7 de $\mathrm{pH}$ em sistemas terrígenos.

O ponto 2 de monitoramento da qualidade das águas apresenta uma característica distinta dos demais pontos, sendo uma das nascentes do rio Sucuri e possui níveis mais baixos de OD, com $5,03 \mathrm{mg} / \mathrm{L}$, devido ao baixo turbilhonamento, o que ocasionou seu enquadramento na classe II, o pior dentre todos os pontos analisados. Além do fato supracitado, ocorre a mesma taxa elevada do TDS e CE, devido às águas ricas em carbonato de cálcio e magnésio dissolvido da Formação Cerradinho (dolomítica), deixando-a salobra e prejudicando seu enquadramento. Isso, somada à baixa velocidade do fluxo das águas, a dificuldade de renovação da mesma e, somado a matéria orgânica que caem das árvores (folhas e galhos) e permanece por longo período de tempo, faz com que as águas apresentem uma qualidade mais baixa em seu enquadramento.

O ponto 3 apresenta maior volume e velocidade das águas, localizado em mata fechada úmida. Contudo, as muitas surgências à montante deste ponto, fez com que a $\mathrm{CE}$ permanecesse elevada, apresentando pH levemente alcalino e TDS elevado. Este terceiro ponto encontra-se localizado a 106 metros da nascente principal, ocorrendo um maior turbilhonamento da água. O aumento da velocidade do fluxo ocasiona sua oxigenação, elevando os níveis de OD para 6,17 
$\mathrm{mg} / \mathrm{L}$, o que melhorou seu enquadramento e enquadrou novamente este setor do rio Sucuri na Classe I.

O ponto 4, localizado no médio curso da BHRS, apresenta maior volume de água, mas mesmo assim, as águas permaneceram translúcidas, com apenas 0,73 NTU, o que pode ser interpretado pela pouca movimentação dos sólidos em suspensão. Este ponto apresenta contato com o calcário puro da Formação Xaraiés, o que aumentou a alcalinidade das águas para 7,92 de pH e, devido ao turbilhonamento das águas, ocorre a elevação do OD para 8,44 mg/L. Com isso, o rio Sucuri permanece na classe I, com uma manutenção da qualidade das águas, mesmo com a elevação de seu volume no canal.

Por fim, o ponto 5 apresenta características hídricas que não se difere dos demais pontos, com a manutenção do $\mathrm{pH}$ alcalino, devido às rochas que estão no subsolo, especialmente pela influência da Formação Xaraiés. Seu OD permaneceu elevado devido à velocidade de fluxo das águas, o mesmo ocorreu com a CE e TDS. Devido ao processo de decantação dos sedimentos calcários em suspensão, no fundo do canal fluvial, esta água tem reduzida turbidez, apresentando-se níveis excelentes $(0,16 \mathrm{NTU})$. Esses valores de turbidez se constituem um diferencial entre os demais mananciais do Mato Grosso do Sul (Figura 5).

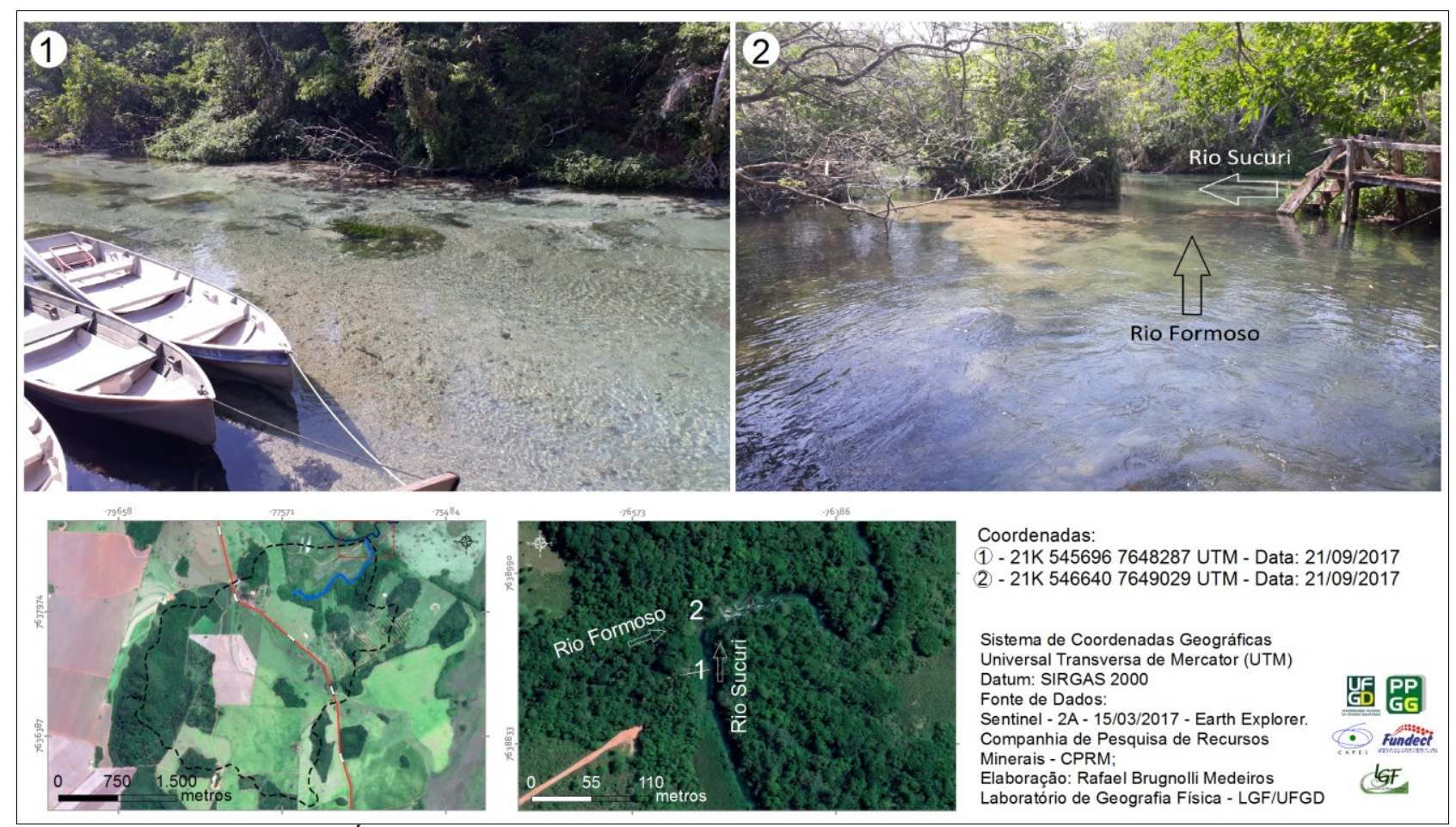

Figura 5- Águas do rio Sucuri (1) e confluência do rio Sucuri com o rio Formoso (2).

Na sua foz, o rio Sucuri apresenta maior volume de água do que o rio Formoso, sobretudo por ser o primeiro grande afluente do Formoso no alto curso, muito próximo à serra da Bodoquena. Logo, o rio Sucuri exerce forte influência sobre o rio Formoso, o que melhora seu nível de 
translucidez das águas, eleva-se a oxigenação, consolida-se a CE e o TDS elevado, assim como o $\mathrm{pH}$ alcalino, dentre outros parâmetros analisados nessa pesquisa e que apresentam forte influência hidrogeológica.

\section{CONCLUSÕES}

A BHRS possui grande influência das rochas das formações Cerradinho (calcários dolomíticos), Bocaina (dolomíticos silicosos), Xaraiés (tufas calcárias e travertinos) e da Subunidade Carbonática do Grupo Cuiabá (mármores calcíticos e dolomíticos). Ou seja, com toda a sua extensão apresentando rochas ricas em carbonato de cálcio provenientes dos ambientes cársticos, refletem no manancial hídrico uma série de propriedades, que diferem dos ambientes terrígenos.

A alcalinidade das rochas, devido à dissolução do calcário nas águas, é uma das características mais destacadas, traduzida na decantação das impurezas e na elevada translucidez de suas águas. Assim, estas águas chegam a níveis considerados excelentes pela Resolução CONAMA $357 / 2005$, sendo enquadrados na classe Especial. Outro fator de destaque são os altos valores de condutividade elétrica e de sólidos totais dissolvidos, características típicas, geradas por sais dissolvidos provenientes de carbonatos, bicarbonatos e magnésio, que são bons condutores elétricos.

Com relação à oxigenação das águas, 4 dentre os 5 pontos de monitoramento apresentaram valores satisfatórios. Apenas o ponto 2 que, por estar localizado em uma área com pouca velocidade de fluxo, com grande quantidade de matéria orgânica e por ser uma área de ressurgência, apresenta pequena concentração de oxigênio dissolvido, se comparado com os outros quatro pontos analisados.

De forma geral, a BHRS apresentou boa qualidade das águas superficiais. Foram encontradas variações em suas características químicas ao longo do seu curso, entretanto, estas águas são consideradas como classe I. Tais informações demonstram a necessidade de contínuo estudo sobre a bacia do rio Sucuri, monitorando as águas em outras estações do ano, comparando-as e identificando possíveis influências dos aspectos físicos e antrópicos nas águas dessa importante bacia hidrográfica de Bonito.

\section{AGRADECIMENTOS}

À Fundação de Apoio ao Desenvolvimento do Ensino, Ciência e Tecnologia do Estado do Mato Grosso do Sul (FUNDECT) e à Coordenação de Aperfeiçoamento de Pessoal de Nível Superior (CAPES). 


\section{REFERÊNCIAS}

AQUAAMBIENTE. 2004. Tratamento Águas Potáveis. 32 p. Disponível em: http://mariorebola.com/home/wp-content/uploads/2011/09/AquaAmbiente-Tratamento-de-\%C.pdf.

Acesso em: 20 abr. 2016.

BARTMANN, R. A. Variabilidade Físico-Química das águas da sub-bacia do Rio Miranda-MS. 2015, 120 f. Dissertação (Mestrado em Geografia) - Universidade Federal de Mato Grosso do Sul. Três Lagoas, 2015.

BOGgiani, P. C. Análise estratigráfica da bacia Corumbá (Neoproterozóico) - Mato Grosso do Sul. 1997. 181 f. Tese (Doutorado em Geociências) - Instituto de Geociências, Universidade de São Paulo, São Paulo, 1997.

BRASIL. CONSELHO NACIONAL DO MEIO AMBIENTE - CONAMA. Resolução 357/2005, dispõe sobre a classificação dos corpos de água e diretrizes ambientais para o seu enquadramento, bem como estabelece as condições e padrões de lançamento de efluentes, e dá outras providências. Governo Federal, Brasília. Publicada no DOU n 92, de 17 de março de 2005, Seção 1, 89 p.

BRASIL. Lei $\mathbf{n}^{0}$ 9.433, de 8 de janeiro de 1997. Institui a Política Nacional de Recursos Hídricos, cria o Sistema Nacional de Gerenciamento de Recursos Hídricos, regulamenta o inciso XIX do art. 21 da Constituição Federal, e altera o art. $1^{\circ}$ da Lei ${ }^{\circ}$ 8.001, de 13 de março de 1990, que modificou a Lei $\mathrm{n}^{\circ}$ 7.990, de 28 de dezembro de 1989.

BRUGNOLLI, R. M. Procedimentos Metodológicos para análise da Vulnerabilidade Ambiental em Bacias Hidrográficas com um Estudo de caso da Bacia Hidrográfica do Córrego Moeda, Três Lagoas/MS em 2014. 2016. 341 f. Dissertação (Mestrado em Geografia) - Universidade Federal de Mato Grosso do Sul, Três Lagoas. 2016.

- Zoneamento Ambiental para o Sistema Cárstico da Bacia Hidrográfica do Rio Formoso, Mato Grosso do Sul. 2020. 403 f. Tese (Doutorado em Geografia) - Faculdade de Ciências Humanas, Universidade Federal da Grande Dourados, Dourados, 2020.

BRUGNOLLI, R. B.; BEREZUK, A. G. ; PINTO, A. L. . Qualidade e Enquadramento das Águas Superficiais da Bacia Hidrográfica do Rio Mimoso, Bonito/MS. Revista Ciência Geográfica, v. 23, p. 184-195, 2019.

BRUGNOLli, R. B.; PINTO, A. L.; MIGUEL, A. E. S. Influência do Uso e Manejo Florestal dos Hortos de Eucalipto na Qualidade das Águas Superficiais da Bacia Hidrográfica do Córrego Moeda, Três Lagoas/MS. Revista de Geografia, Recife, v. 34, p. 186-200, 2017.

FRITZSONS, E. Avaliação temporal da qualidade de água como diagnóstico do uso e ocupação das terras na bacia do Alto Capivari, Região Cárstica Curitibana. 2003. 190 f. Tese (Doutorado em Engenharia Florestal) - Setor de Ciências Agrárias, Universidade Federal do Paraná. Curitiba, 2003.

IVO, D.; KUBICA, R. A instrumentação analítica utilizada na obtenção de água purificada para produção de fármacos: foco na importância da calibração. 2009. Disponível em: http://www.labsoft.com.br/arquivos/artigos/CT-038_09.pdf. Acesso em: 05 mai. 2016.

LELIS, L. R. M.; PINTO, A. L.; SILVA, P. V.; PIROLI, E. L.; BRUGNOLLI, R. B.; GOMES, W. M. Qualidade das Águas Superficiais da Bacia Hidrográfica do Rio Formoso, Bonito - MS. Revista Formação, Presidente Prudente, v. 2, p. 279-302, 2015. 
LIBÂNIO, M. Fundamentos de qualidade e tratamento de água. 1. ed. Campinas: Átomo, 2005. $638 \mathrm{p}$.

MANTOVANI, L. E.; FRITZSONS, E.; WREGE, M. S. Aspectos Hidrológicos e Hidrogeológicos da Bacia do Rio Fervida, Aquífero Carste, Colombo, Paraná. Revista Ra'e Ga, Curitiba, v. 37, p. 190-206, 2016.

MATO GROSSO DO SUL. Lei $\mathbf{n}^{\mathbf{0}} \mathbf{2 . 4 0 6}$, de 29 de janeiro de 2002. Institui a Política Estadual dos Recursos Hídricos, cria o Sistema Estadual de Gerenciamento dos Recursos Hídricos e dá outras providências. Brasília, Publicada no Diário Oficial nº 5.907, de 30 de dezembro de 2002.

MONTEIRO, J. P.; SILVA, M. L.; CARREIRA, P. M.; SOARES, A. M. Aplicação de Métodos Geoquímicos Isotópicos à Interpretação da Hidrodinâmica do Aquífero Carbonatado da Serra de S. Mamede (Castelo de Vide). In: CONGRESSO DE ESPANHA DE GEOQUÍMICA. 7., Madrid. Anais... Madrid: Cedex, 1997. p. 544-551.

OLIVEIRA, G. H.; PINTO, A. L.; FERNANDES, M. V. F.; ARAUJO, A. F. Balneabilidade no baixo Sucuriú, município de Três Lagoas/MS. Revista de Geografia, Meio Ambiente e Ensino - GEOMAE, v. 2, p. 79-89, 2011.

PINTO, A. L.; OLIVEIRA, G. H.; PEREIRA, G. A. Avaliação da Eficiência da Utilização do Oxigênio Dissolvido como Principal Indicador da Qualidade das Águas Superficiais da Bacia do Córrego Bom Jardim, Brasilândia/MS. Revista de Geografia, Meio Ambiente e Ensino - GEOMAE, v. 1, p. 69-82, 2010.

PIROLI, E. L. Geoprocessamento aplicado ao estudo do uso da terra das áreas de preservação permanente nos corpos d'agua da bacia hidrográfica do Rio Pardo. 2013. 150 f. Tese (Livre Docência em Sensoriamento Remoto e Geoprocessamento) - Universidade Estadual Paulista, Ourinhos, 2013.

SALLUN FILHO, W.; KARMANN, I.; BOGGIANI, P. C.; STEMBRINO, P.; CRISTALLI, P. de S.; UTIDA, G. A Deposição de Tufas Quaternárias no Estado de Mato Grosso do Sul: Proposta de Definição da Formação Serra da Bodoquena. Revista de Geologia USP, São Paulo, v. 9, n. 3, p. 47-60, 2009.

SCHAUTZ, L. C. A. Avaliação da qualidade da água do Rio Dourados/MS - Variáveis FísicoQuímicas. Dourados/MS. 2015. 63 f. Dissertação (Mestrado em Química) - Faculdade de Ciências Exatas e Tecnologia, Universidade Federal da Grande Dourados, Dourados, 2015.

SILVA, P. V.; PIROLI, E. L.; HERNÁNDEZ, J. E. G. Qualidade da água e turismo em bacias hidrográficas: o caso da microbacia do Rio Sucuri, Bonito-MS, Brasil. Revista Ciência Geográfica, Bauru, v. 18, n. 18. p. 89-101, 2014.

SILVA, P. V.; PIROLI, E. L.; PINTO, A. L. Água e Turismo na Bacia do Rio Formoso em Bonito-MS: Percepção dos Turistas. Revista Formação, Presidente Prudente, v. 2, n. 23, p. 287-310, 2016. 